\title{
Ethylene-Octene Copolymers/Organoclay Nanocomposites: Preparation and Properties
}

\author{
Alice Tesarikova, ${ }^{1}$ Dagmar Merinska, ${ }^{1,2}$ Jiri Kalous, ${ }^{1,2}$ and Petr Svoboda ${ }^{1}$ \\ ${ }^{1}$ Department of Polymer Engineering, Faculty of Technology, Tomas Bata University in Zlin, Nam. T. G. Masaryka 275, \\ 76272 Zlin, Czech Republic \\ ${ }^{2}$ Centre of Polymer Systems, University Institute, Tomas Bata University in Zlin, Nad Ovcirnou 3685, 76001 Zlin, Czech Republic \\ Correspondence should be addressed to Petr Svoboda; svoboda@ft.utb.cz
}

Received 29 September 2015; Revised 8 December 2015; Accepted 10 December 2015

Academic Editor: Antonios Kelarakis

Copyright (C) 2016 Alice Tesarikova et al. This is an open access article distributed under the Creative Commons Attribution License, which permits unrestricted use, distribution, and reproduction in any medium, provided the original work is properly cited.

\begin{abstract}
Two ethylene-octene copolymers with 17 and 45 wt.\% of octene (EOC-17 and EOC-45) were compared in nanocomposites with Cloisite 93A. EOC-45 nanocomposites have a higher elongation at break. Dynamical mechanical analysis (DMA) showed a decrease of $\tan \delta$ with frequency for EOC-17 nanocomposites, but decrease is followed by an increase for EOC-45 nanocomposites; DMA showed also increased modulus for all nanocomposites compared to pure copolymers over a wide temperature range. Barrier properties were improved about $100 \%$ by addition of organoclay; they were better for EOC-17 nanocomposites due to higher crystallinity. X-ray diffraction (XRD) together with transmission electron microscopy (TEM) showed some intercalation for EOC-17 but much better dispersion for EOC-45 nanocomposites. Differential scanning calorimetry (DSC) showed increased crystallization temperature $T_{c}$ for EOC-17 nanocomposite (aggregates acted as nucleation agents) but decrease $T_{c}$ for EOC-45 nanocomposite together with greatly influenced melting peak. Accelerated UV aging showed smaller $\mathrm{C}=\mathrm{O}$ peak for EOC-45 nanocomposites.
\end{abstract}

\section{Introduction}

Polymer nanocomposites have been interesting already for a longer period of time. They represent the group of systems where polymer matrix is mixed with a certain type of nanofiller. One of the fillers is a type from layered silicate minerals when the thickness of the individual leaves is in nanometer size. The most frequently used type of nanoclay is montmorillonite (MMT) [1-5]. It is a layered mineral belonging to a group of clay minerals with octahedral and tetrahedral nets in the ratio of $2: 1$. Because of the problems with the exfoliation of its agglomerates in the polymeric matrix, MMT is used not pure but modified by the process known as organofilization or intercalation, that is, the insertion of a suitable organic compound into MMT interlayer [6-9]. The result of this step brings a broader $D$-spacing as well as a reduction of dispersing forces between the individual platelets of montmorillonite. The role of MMT nanoplatelets in the polymer matrix can be considered from various points of views. Generally, the first one is the original effect of the filler-especially the improvement of mechanical properties [10-13]. The advantage of nanofillers lies in the ability to create this improvement by much lower loading in comparison with common fillers. Another quality of nanoleaves is their positive impact on the orientation of long thick platelets in polymer matrix during compounding (mainly at extrusion/blowing of packaging films), where they create by their orientation a gas barrier to the gas transmission. Thus, the gas permeability is lower. The principle of this phenomenon is shown in Figure 1, where the imagination of an ideal situation-perfect exfoliation of the filler particles together with the perfect orientation of all MMT platelets in polymer matrix-is presented.

Next to the commonly used polyethylene (PE) or polypropylene (PP) matrices from the group of the polymer also some a little bit special types of these polymer matrices 


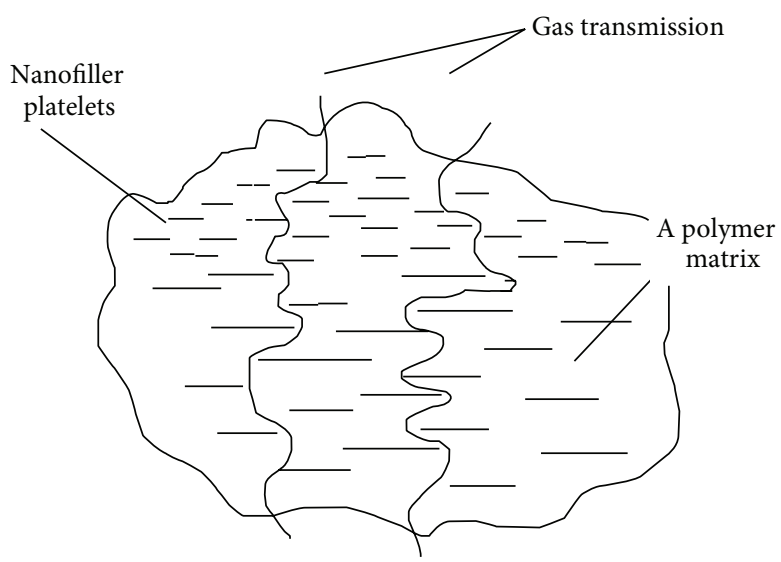

FIGURE 1: Improved barrier properties of nanocomposites.

are studied. One of them can be an ethylene-octene copolymer (EOC) and alternatively its blends with other polymer matrices, mostly PP [1-3].

The ethylene-octene copolymer (EOC), a new polyolefin elastomer, developed by Dow Chemical Company (Delaware, USA) with metallocene catalysis, is interesting by its properties and is attracting a lot of attention from both research and industry [14-16]. EOC is an ethylene based elastomer, so it brings an excellent compatibility with polyolefins, such as polyethylene and PP [17-20]. The presence of the octene comonomer in EOC causes a lower level of crystallinity and a higher flexibility in the copolymer. EOC can be considered as an elastomeric polymer, and usually the octene content in the copolymer varies under $20 \mathrm{wt} . \%$ [21, 22]. Blends of $\mathrm{PP} / \mathrm{EOC}$ may provide enhanced impact properties and can be used, for example, in extruded or molded automotive exterior and interior parts, housing appliances, and other low-temperature applications. Pelletized EOC exhibits easy handling, mixing, and processability. Based on these properties, EOC is currently being used as an impact modifier of $\mathrm{PP}$ to replace ethylene propylene rubber (EPR) and ethylene propylene diene rubber (EPDM) [19, 23, 24].

As it was mentioned above, EOC significantly improves the impact strength, but it causes a decrease of the tensile strength and stiffness of PP [25-27]. Therefore, $\mathrm{PP} / \mathrm{EOC} / \mathrm{mineral}$ filler-based composites have been studied in order to enhance the toughness and stiffness of PP simultaneously. These systems are double-phased [23-25]. Mineral fillers with high aspect ratio, that is, clay nanofillers, have been found to increase stiffness and strength to the thermoplastic polyolefins; they provide a greater possibility for energy transfer from one phase to another [28-31].

However, comparative evaluation of the mechanical and thermal properties of composites based on PP, EOC, and mineral fillers is still limited.

The aim of this work was to add more information about the properties of EOC copolymer with clay nanofiller in order to evaluate the influence of used nanofiller and its concentration on the EOC copolymer. EOC matrix with nanoclay was chosen because this polymer matrix can be considered as one of tie layers of multilayer packaging films with the better end of use properties.

\section{Materials and Methods}

2.1. Materials. Polymer matrices used as carrier materials were ethylene-octene copolymers: Engage 8842 and Engage 8540 (both of DuPont DOW Elastomers, Europe GMBH, Switzerland)-linear formula $\left(\mathrm{CH}_{2} \mathrm{CH}_{2}\right)_{x}\left[\mathrm{CH}_{2} \mathrm{CH}\left[\left(\mathrm{CH}_{2}\right)_{5} \mathrm{CH}_{3}\right]\right]_{y}$ (see Figure 2).

To increase compatibility between the polymer matrix and the filler maleinized polyethylene (PE-MA) Priex 12043 (ADDCOMP Holland BV) in 5 wt.\% concentration was used.

EOC-45 (Engage 8842) is an ultralow density copolymer (see Table 1) that offers exceptional properties of an ultralow density elastomer with the added potential of handing this polymer in pellet form. It has excellent flow characteristics and provides superb impact properties in blends with polypropylene (PP) and polyethylene (PE).

EOC-17 (Engage 8540) is a polyolefin elastomer that is well suited for foam applications and offers excellent performance for profile extrusion of tubing and hoses.

Organically modified montmorillonite (MMT) with trade name Cloisite 93A (Southern Clay Products, Inc.) was used. This type of nanoclay is modified by organic branches of type: dimethyl, hydrogenated tallow, 2-ethylhexyl, and quartenary ammonium methylsulfate; this type is recommended for nonpolar polymer matrices.

The quantity of the above-mentioned nanofiller added to the polymeric matrix was 3,5 , or $7 \mathrm{wt} . \%$.

2.2. Sample Preparation. Polymers with the fillers were compounded in twin-screw extruder Scientific LTE 20-40; screw diameter was $20 \mathrm{~mm}$ and $L / D$ ratio was $40 / 1$. The temperatures of the individual heating zones and the extrusion head were set from $170^{\circ} \mathrm{C}$ to $205^{\circ} \mathrm{C}$, the rotation speed of screws was $300 \mathrm{rpm}$, and the rotation speed of volumetric feeding screw was $20 \mathrm{rpm}$. The extruded strands were air-cooled and then transferred using a knife mill back to a pelletizer Scherr SGS-50E.

Specimens for measurement of properties were prepared by compression molding and cutting. Blends in the form of pellets were placed between two PET sheets preventing the contact with air and thus oxidative degradation. The material was pressed in a mold with size $125 \times 125 \times 2 \mathrm{~mm}$ (for platelets). The pressing time was 5 minutes for platelets (thickness approximately $2 \mathrm{~mm}$ ) and 3 minutes for films (thickness about $50 \mu \mathrm{m}$ ); pellets are molded without a frame, only between two plates of the machine. After that, the mold with material was placed into a water-cooled hydraulic press and cooled down to room temperature.

\subsection{Evaluation of Prepared Samples}

2.3.1. Mechanical Properties. Tensile tests are among the most widely used test methods. The test specimen is deformed unidirectional until the break. Tensile testing was performed on tear machines with a range of campaign. Tensile test 
TABLE 1: List of applied polymer materials (information from data sheets).

\begin{tabular}{lcccc}
\hline Name & Abbreviation & $\begin{array}{c}\text { Octene } \\
\text { content } \\
(\text { wt.\%) }\end{array}$ & $\begin{array}{c}\text { Density } \\
\left(\mathrm{g} / \mathrm{cm}^{3}\right)\end{array}$ & $\begin{array}{c}T_{m} \\
\left({ }^{\circ} \mathrm{C}\right)\end{array}$ \\
\hline Engage 8540 & EOC-17 & 17 & 0.908 & 104 \\
Engage 8842 & EOC-45 & 45 & 0.857 & 38 \\
\hline
\end{tabular}

$$
\left(-\mathrm{CH}_{2} \mathrm{CH}_{2}\right)_{x}\left(\begin{array}{r}
\mathrm{CH}_{2} \mathrm{CH}- \\
\mathrm{CH}_{3}\left(\mathrm{CH}_{2}\right)_{4} \mathrm{CH}_{2}
\end{array}\right)_{y}
$$

FIGURE 2: The structural formula of the ethylene-octene copolymer.

measures the deformation of the sample and the force required for deformation.

Tensile tests were measured at the Faculty of Technology in Tomas Bata University in Zlin (FT TBU). On tensile testing machine Galbadini Quasar 25, EN ISO 527-3 (64 0604), was used; for the speed of tearing 2 initial speed was $1 \mathrm{~mm} / \mathrm{min}$ to the module $2 \%$, and then the speed was increased to $100 \mathrm{~mm} / \mathrm{min}$ until rupture. For tensile strength, elongation at break and tensile modulus were measured and evaluated.

2.3.2. Dynamic Mechanical Analysis (DMA). $\tan \delta$ (tan delta) damping which is the tangent of the phase angle and the ratio of $E^{\prime \prime} / E^{\prime}$ for room temperature in range $1-200 \mathrm{~Hz}$ with step $2 \mathrm{~Hz}$ and for temperature in the range $-100^{\circ} \mathrm{C}$ to $+100^{\circ} \mathrm{C}$ with at $1 \mathrm{~Hz}$ and amplitude $50 \mu \mathrm{m}$ were measured. DMA measurements were performed on samples of size $20 \times 5 \mathrm{~mm}$ made from premolded panels on the device DMA Perkin Elmer in laboratories of FT UTB Zlin.

2.3.3. Gas Barrier Properties (GTR). Observed nanocomposite molded films with the thickness of about $50 \mu \mathrm{m}$ and diameter $80 \mathrm{~mm}$ at a pressure 2 bar and a temperature of $35^{\circ} \mathrm{C}$ were used for the measurement of $\mathrm{N}_{2}, \mathrm{O}_{2}$, and $\mathrm{CO}_{2}$ permeability on the equipment known as Julabo TW8 based on CSN 64 0115, method of a constant volume. The conversion of the results according to standard ASTM D 3985-05 was performed.

2.3.4. XRD Analysis. In FT TBU laboratories, X-ray diffraction analysis (XRD) was also performed. The instrument diffractometer URD 6 was used. Measurements were done in the reflection mode in the $2 \theta$ range of $2-30^{\circ}$ at a voltage of $40 \mathrm{kV}$ and $30 \mathrm{~mA}$ with a step size of $0.0263^{\circ}$. Information from X-ray analysis, complemented by TEM, provides us with information on the morphology of the nanocomposites.

\subsubsection{Transmission Electron Microscopy (TEM). Dispersion} of the clays in polymer matrix and nanostructures was observed through microscopic investigations.

Samples of $40 \times 20 \mathrm{~mm}$ made from molded plates were sent to IMC Prague, where TEM observation was performed. Ultrathin sections prepared on special ultracryomicrotome LEICA at $-100^{\circ} \mathrm{C}$ were used as samples, temperature of the knife was $-50^{\circ} \mathrm{C}$, and thickness was of about $50 \mathrm{~nm}$. Transmission electron microscopy was performed on a JEM $200 \mathrm{CX}$ at an accelerated voltage of $100 \mathrm{kV}$.

2.3.6. Thermal Analysis: Differential Scanning Calorimetry (DSC). The samples on the Mettler Toledo DSC 1 with an external cooling unit and purging the chamber with nitrogen gas were observed. The rate of cooling and heating was $20^{\circ} \mathrm{C}$ per minute and the temperature range was $-90^{\circ} \mathrm{C}$ to $150^{\circ} \mathrm{C}$.

2.3.7. Accelerated Weathering Test. Samples about $5 \times 15 \mathrm{~cm}$ for accelerated UV degradation test according to EN ISO 4892 - 2nd ingestion device-Xenotest Alpha were prepared. The measurement conditions were as defined in abovementioned standard (temperature was $38^{\circ} \mathrm{C}$, irradiance $60 \mathrm{Wh} / \mathrm{m}^{2}$ filters simulating daylight, and RH 50\%). One measurement cycle (46 days) simulates the degradation of one year.

2.3.8. Fourier Transform Infrared Spectroscopy (FTIR). The test on the FTIR spectrometer AVATAR 320 (Nicolet) which is a standard single-beam FTIR spectrometer operating in the range of wave numbers 4000 to $500 \mathrm{~cm}^{-1}$ was performed. FTIR instrument is controlled via a PC using the software Omnic. The measurement by the ATR (attenuated reflection method) was carried out.

\section{Results and Discussion}

3.1. Mechanical Properties. Polymer/clay nanocomposites have been studied for longer period of time as materials that could be used in packaging industry. Two types of Engage (ethylene-octene copolymer)/clay nanocomposites in this paper are reported. This work is particularly focused on the mechanical, barrier, and morphology properties.

Table 2 presents the mechanical properties of two types of EOC with nanofiller Cloisite 93 in the polymer matrix. As can be seen, the values of the tensile strength of EOC are the same in comparison to materials enriched by filler Cloisite 93. It can be assumed that the presence of filler in samples, compared to the neat ones, does not have a significant effect on the change of mechanical properties.

Figure 3 illustrates tensile stress as a function of strain for pure EOC-17 (45) and EOC with 5\% of Cloisite 93; in Table 2 the values for filler contant 3,5 , and $7 \mathrm{wt} . \%$ are listed. EOC-17 exhibits yield point and higher values of stress. This is caused by the presence of lamellar crystals. Higher content of octene groups in EOC- 45 causes much lower presence of crystals and the crystals are not lamellar but very small "spot-like" [17]. This unique morphology is responsible for lower modulus (higher softness), absence of yield point, and better elasticity (which is illustrated in Table 2). Presence of nanoclay caused higher stress value, in case of EOC-17 during the whole test; in case of EOC-45 it caused higher elongation. For example, the yield point of EOC-17 increased by addition of $5 \mathrm{wt} . \%$ of nanoclay from 7.41 to $9.28 \mathrm{MPa}$ (see Figure 3(a)). During the tensile test the orientation of crystals caused increase in stress for all samples. 
TABLE 2: Tensile tests of pure EOC-17, EOC-45, and filled EOC-17 and EOC-45 with 3, 5, and 7 wt.\% of nanoclay Cloisite 93.

\begin{tabular}{lcccc}
\hline Composition & Tensile strength $(\mathrm{MPa})$ & Std. dev. & Ductility (a.u.) & $E$ modulus (MPa) \\
\hline EOC-17 pure & 30.950 & 2.4 & 10.8237 & 25.34 \\
EOC-17 + 3\% Cloisite 93 & 26.767 & 2.4 & 9.0378 & 24.56 \\
EOC-17 + 5\% Cloisite 93 & 28.458 & 2.5 & 9.1541 & 24.65 \\
EOC-17 + 7\% Cloisite 93 & 25.117 & 2.6 & 8.3711 & 24.38 \\
EOC-45 pure & 6.950 & 0.4 & 18.5486 & 2.16 \\
EOC-45 + 3\% Cloisite 93 & 6.208 & 0.4 & 17.4329 & 2.53 \\
EOC-45 + 5\% Cloisite 93 & 7.400 & 0.3 & 19.4329 & 4.62 \\
EOC-45 + 7\% Cloisite 93 & 5.258 & 0.5 & 11.5429 & 3.43 \\
\hline
\end{tabular}

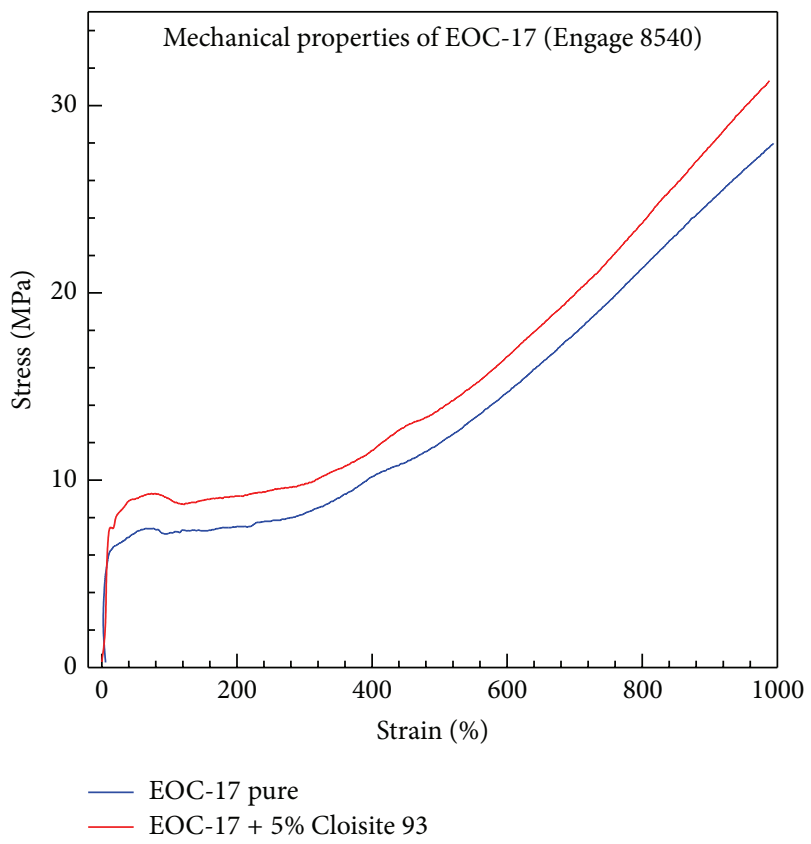

(a)

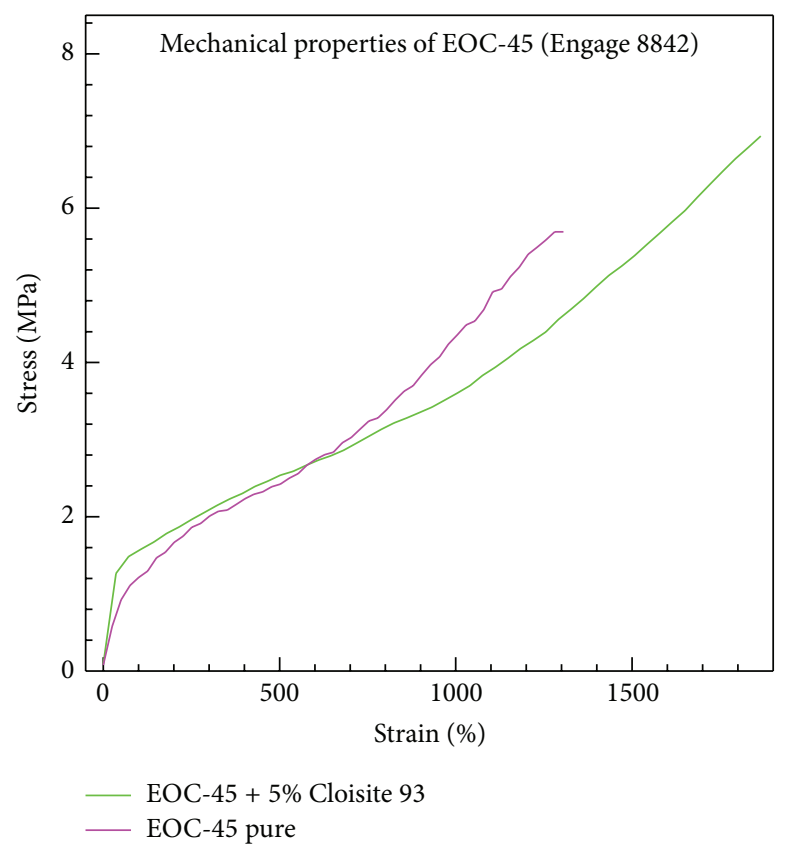

(b)

Figure 3: Mechanical properties of (a) EOC-17 (Engage 8540) with 5 wt.\% Cloisite 93 and (b) EOC-45 (Engage 8842) with 5 wt.\% Cloisite 93.

After the tensile test we have measured also the residual strain. EOC-45 samples exhibit better elasticity (lower value of residual strain). The composites have only slightly worse elasticity (slightly higher values of residual strain).

Measuring distance is as follows: $l_{0}=$ initial distance, $l_{1}$ $=$ distance at maximum extension, and $l_{2}=$ distance after 24 hours of relaxation (see Table 3 ).

3.2. Dynamic Mechanical Analysis (DMA). Pure EOC-17 and its blends with Cloisite 93 show a linear decrease of tan delta $(\tan \delta)$ with increasing frequency. The addition of Cloisite 93 causes $\tan \delta$ to drop significantly at high frequencies whereas the low frequencies are affected only marginally.

However, EOC-45 is behaving differently, the addition of Cloisite 93 leads to increased $\tan \delta$, and the increase is higher when compared to pure EOC-45. What remains the same is the marginal effect of Cloisite 93 within low frequencies and much stronger interaction at high frequency. Also the percentage of Cloisite 93 does not affect final values
TABLE 3: Residual strain of pure EOC-17, EOC-45 and filled EOC-17, EOC-45 with 5 wt.\% of nanoclay Cloisite 93.

\begin{tabular}{lccc}
\hline Composition & $l_{0}(\mathrm{~mm})$ & $l_{1}(\mathrm{~mm})$ & $l_{2}(\mathrm{~mm})$ \\
\hline EOC-17 pure & 10 & 80 & 60.1 \\
EOC-17 + 5\% Cloisite 93 & 10 & 90 & 60.5 \\
EOC-45 pure & 10 & 140 & 30.2 \\
EOC-45 + 5\% Cloisite 93 & 10 & 145 & 30.5 \\
\hline
\end{tabular}

of $\tan \delta$; EOC-45 possesses a high percentage of octene chains (45 wt.\%) compared to 17 wt.\% of EOC-17. As we can see in Figure 4, the driving force for different mechanical behavior is interaction with Cloisite 93.

Results and curves of tan delta versus frequency were very similar for 3, 5, and $7 \mathrm{wt} . \%$ Cloisite 93; therefore, we used results of the dependence on the frequency and the temperature only for $5 \mathrm{wt}$.\% concentration level. According to our previous experience the $5 \%$ nanoclay filling is optimal. 


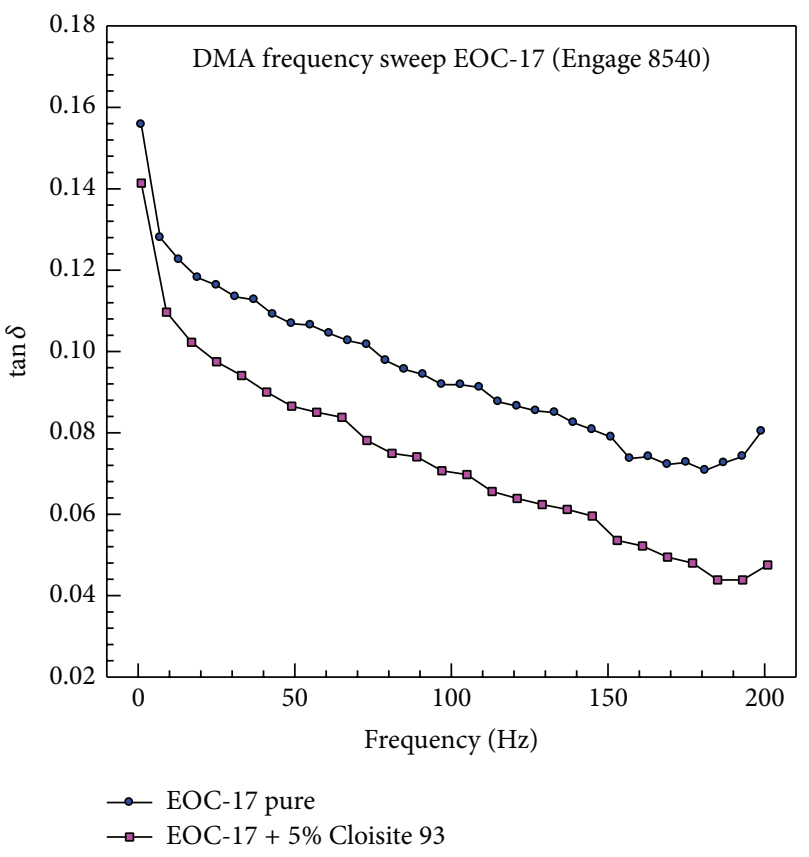

(a)

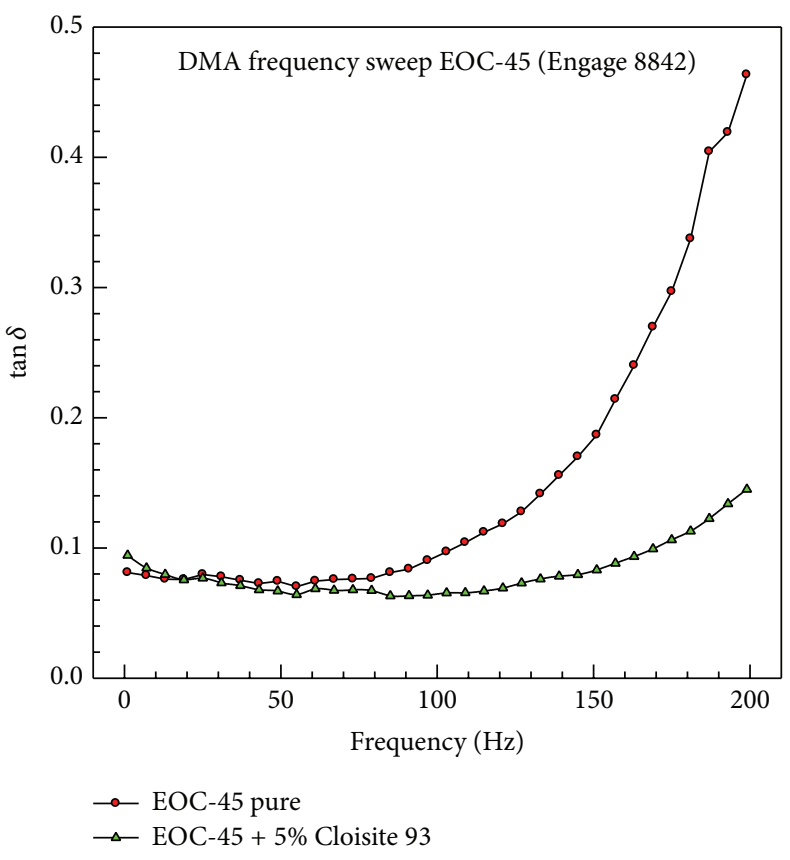

(b)

FIGURE 4: DMA graphs of (a) EOC-17 (Engage 8540) with 5 wt.\% Cloisite 93 and (b) EOC-45 (Engage 8842) with 5 wt.\% Cloisite 93 at room temperature.

TABLE 4: Dependence of tan delta and $E^{\prime}$ modulus on the temperature for pure EOC-17, EOC-45, and filled EOC.

\begin{tabular}{|c|c|c|c|c|c|c|c|}
\hline \multirow{2}{*}{ Composition } & \multicolumn{7}{|c|}{ Temperature $\left({ }^{\circ} \mathrm{C}\right)$} \\
\hline & -90 & -60 & -30 & 0 & 30 & 60 & 90 \\
\hline & \multicolumn{7}{|c|}{$\tan \delta$} \\
\hline EOC-17 pure & 0.0893 & 0.0215 & 0.0626 & 0.1106 & 0.1669 & 0.1885 & 0.0579 \\
\hline EOC-17 + 5\% Cloisite 93 & 0.0312 & 0.0205 & 0.0576 & 0.0931 & 0.1482 & 0.2000 & 0.1262 \\
\hline EOC-45 pure & 0.1314 & 0.1370 & 0.2551 & 0.0701 & 0.0824 & - & - \\
\hline \multirow[t]{2}{*}{ EOC- $45+5 \%$ Cloisite 93} & 0.0742 & 0.0978 & 0.2413 & 0.0762 & 0.0987 & - & - \\
\hline & \multicolumn{7}{|c|}{$E^{\prime}$ modulus $(\mathrm{MPa})$} \\
\hline EOC-17 pure & 1258 & 1197 & 871 & 356 & 147.6 & 47.09 & 19.10 \\
\hline EOC-17 + 5\% Cloisite 93 & 1552 & 1460 & 1078 & 498 & 237.7 & 77.31 & 28.59 \\
\hline EOC-45 pure & 537 & 436 & 26.4 & 8.21 & 4.01 & - & - \\
\hline EOC- $45+5 \%$ Cloisite 93 & 841 & 701 & 59.9 & 19.4 & 9.79 & - & - \\
\hline
\end{tabular}

$\tan \delta$ was lower for both of the EOC filled nanocomposites. At lower frequencies the EOC-45 and EOC-45 nanocomposites exhibit lower value of $\tan \delta$ (better elasticity). This is caused by lower crystallinity and also by defect that the crystals are "spot-like" while in EOC-17 there are normal lamellar crystals. At frequencies higher than $100 \mathrm{~Hz}$ we found increase of $\tan \delta$ for EOC-45. The test was performed at room temperature which is rather close to melting point. The macromolecules lose the ability to return to original shape during the high-frequency test. The nanofiller decreases the amount of deformation; therefore the $\tan \delta$ values are lower (see Figure 4).

The dependency of $E^{\prime}$ modulus on temperature is similar for both materials and nanocomposites (Figure 5 and Table 4). After reaching glass transmission temperature, modulus shows sharp drop and both compounds possess higher modules in almost whole temperature range with the exception of temperature close to melting point. Strengthening effect of Cloisite is stronger in EOC-17 nanocomposite when compared to EOC-45, in addition to increased modulus, glass transition and melting temperatures are slightly shifted to higher temperatures.

Both nanocomposites show similar behavior in $\tan \delta$; temperature dependency Cloisite 93 increases tan delta. Mentioned increase is more significant at the peak position of the curve. The compound of EOC-17 with 5 wt.\% Cloisite 93 loses tan delta much less compared to pure EOC-17, and when the temperature approaches melting point, it retains significantly higher $\tan \delta$. On the other hand, EOC-45 with Cloisite 93 loses tan delta at the same rate as pure EOC-45, 


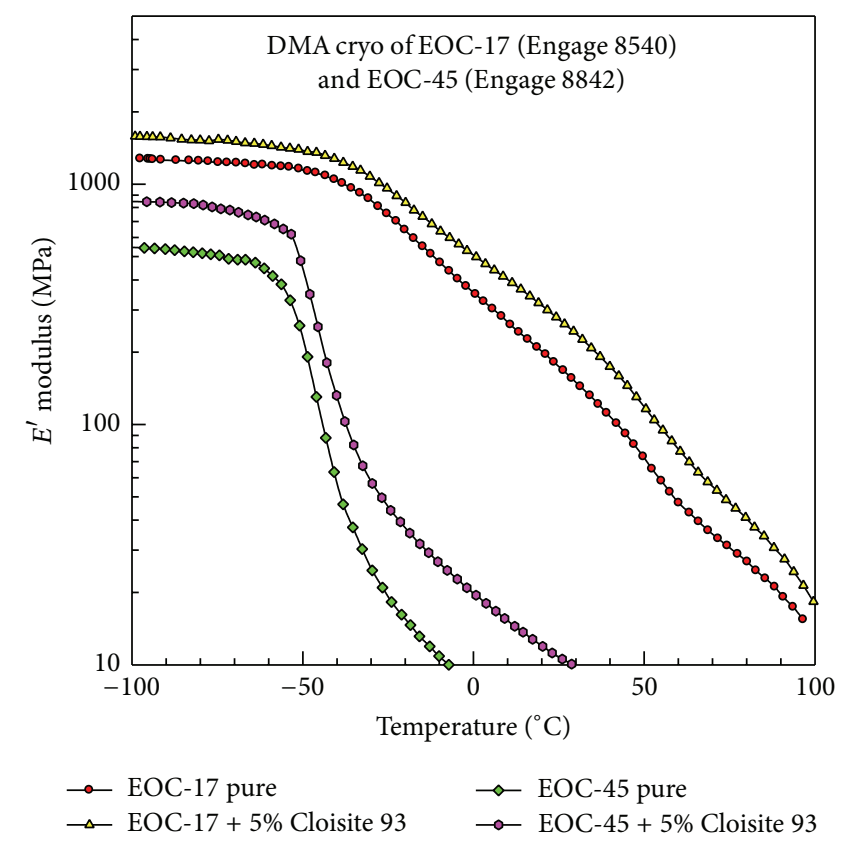

(a)

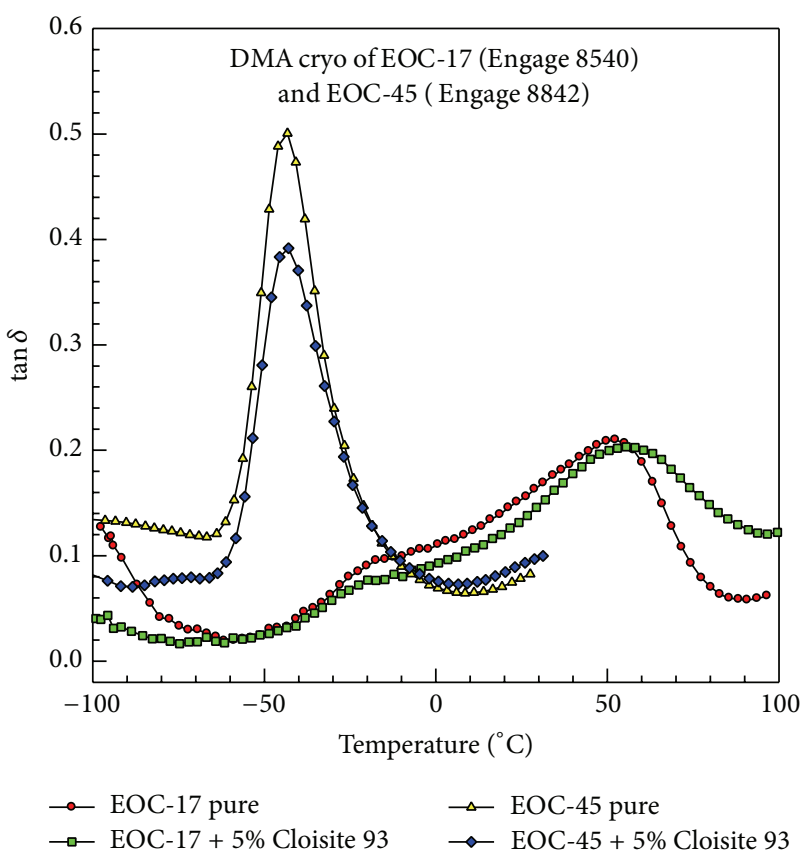

(b)

Figure 5: DMA graphs temperature dependencies: EOC-17 (Engage 8540) with 5 wt.\% Cloisite 93 and EOC-45 (Engage 8842) with 5 wt.\% Cloisite 93: (a) $\log E^{\prime}$ modulus and (b) $\tan \delta$.

but the maximal increase at peak point is higher than EOC17. Another difference is visible when close to melting point temperatures: the volume of side chains does change the effect of Cloisite 93 on EOC behavior.

Curves can be influenced by the low thermal conductivity of polymer samples. The $E^{\prime}$ modulus values were higher for the nanocomposites at all temperatures.

With increasing temperature the $E^{\prime}$ modulus decreases for all samples, especially above $-50^{\circ} \mathrm{C}$, nanofiller increases the modulus greatly at temperatures above $T_{m}$ which is at this graph visible only for EOC- 45 (with $T_{m}$ around $50^{\circ} \mathrm{C}$ ).

Figure 5(b) illustrates decrease from 0.5 to 0.39 . The position of $T_{g}$ (the first peak) did not change in case of EOC17 ; nevertheless above $+50^{\circ} \mathrm{C}$ the presence of nanoclay significantly increased the $\tan \delta$ value which can be interpreted as worse elasticity above this temperature for the nanocomposites. At lower temperatures the $\tan \delta$ values are lower for the nanocomposites which means better elasticity. The worse elasticity at temperature approaching melting point is caused by a flow of the material during mechanical testing which is not prevented by crosslinking (see Figure 5(b)). The nanofiller prevents return of the sample from elongated state at elevated temperatures and thus $\tan \delta$ for the nanocomposites is higher.

3.3. Barrier Properties. As mentioned above, the ethyleneoctene copolymer can be used in packaging industry. Therefore, this study also covers the values of permeability for $\mathrm{N}_{2}$, $\mathrm{O}_{2}$, and $\mathrm{CO}_{2}$, which are mediums that should be prevented from penetrating through the film, for example, in the case of food wrapping. In this instance, films pressed on the manual and hydraulic presses were used as the samples for the measurement.

The evaluation of gas transmission rate and oxygen transmission rate (see Table 5 and Figure 6) is shown for EOC-17 and EOC-45 copolymer/clay nanocomposites. As the results show permeability, pure materials (EOC-17 and EOC$45)$ have inferior properties compared to filled materials. The best combination seems to be of EOC $+5 \%$ Cloisite 93 .

In a comparison of both used ethylene-octene copolymers, EOC-17 shows significantly better properties for all gases. This may be due to lower content of octene groups and higher crystallinity.

It can be concluded that the nanofiller Cloisite 93 can improve the polymer matrix EOC. When applied in EOC matrix the permeability of gases decreases. This may be due to a better distribution and dispersion of filler, or better exfoliation MMT nanolayers in the polymer matrix. It is known that during the pressing of samples it is not possible to suppose an achievement of a perfect orientation of MMT platelets.

Hot plates are pressed in a press machine into very thin films. The thickness of the pressed film is about $50 \mu \mathrm{m}$, and the size of MMT platelets is on the similar level; thus the orientation of MMT leaves, in this case, is not excluded.

3.4. Analysis of the Morphology by XRD. In order to discover the level of montmorillonite exfoliation in used matrices. XRD patterns have been taken. For easier comparison graphs with the curve of neat EOC matrix, of original MMT nanofiller and their mixture, have been summarized (Figure 7). 
TABLE 5: The gas transmission rate for $\mathrm{N}_{2}, \mathrm{O}_{2}$, and $\mathrm{CO}_{2}$.

\begin{tabular}{lcccc}
\hline Composition & $\begin{array}{c}\text { Thickness } \\
(\mathrm{mm})\end{array}$ & $\begin{array}{c}\text { GTR for } \mathrm{N}_{2} \\
\left(\mathrm{~cm}^{3}(\mathrm{STP}) / \mathrm{m}^{2} \cdot \mathrm{den} .0 .1 \mathrm{MPa}\right)\end{array}$ & $\begin{array}{c}\text { GTR for } \mathrm{O}_{2} \\
\left(\mathrm{~cm}^{3}(\mathrm{STP}) / \mathrm{m}^{2} \cdot \mathrm{den} .0 .1 \mathrm{MPa}\right)\end{array}$ & $\begin{array}{c}\mathrm{GTR} \mathrm{for} \mathrm{CO}_{2} \\
\left(\mathrm{~cm}^{3}(\mathrm{STP}) / \mathrm{m}^{2} \cdot \mathrm{den} .0 .1 \mathrm{MPa}\right)\end{array}$ \\
\hline EOC-17 pure & 0.52 & 509 & 1372 & 5361 \\
EOC-17 + 3\% Cloisite 93 & 0.52 & 295 & 789 & 2765 \\
EOC-17 + 5\% Cloisite 93 & 0.53 & 264 & 734 & 2619 \\
EOC-17 + 7\% Cloisite 93 & 0.53 & 386 & 940 & 3541 \\
EOC-45 pure & 0.53 & 3055 & 8060 & 33369 \\
EOC-45 + 3\% Cloisite 93 & 0.53 & 1792 & 4265 & 17874 \\
EOC-45 + 5\% Cloisite 93 & 0.53 & 1683 & 4113 & 16664 \\
EOC-45 + 7\% Cloisite 93 & 0.52 & 2065 & 5391 & 25878 \\
\hline
\end{tabular}

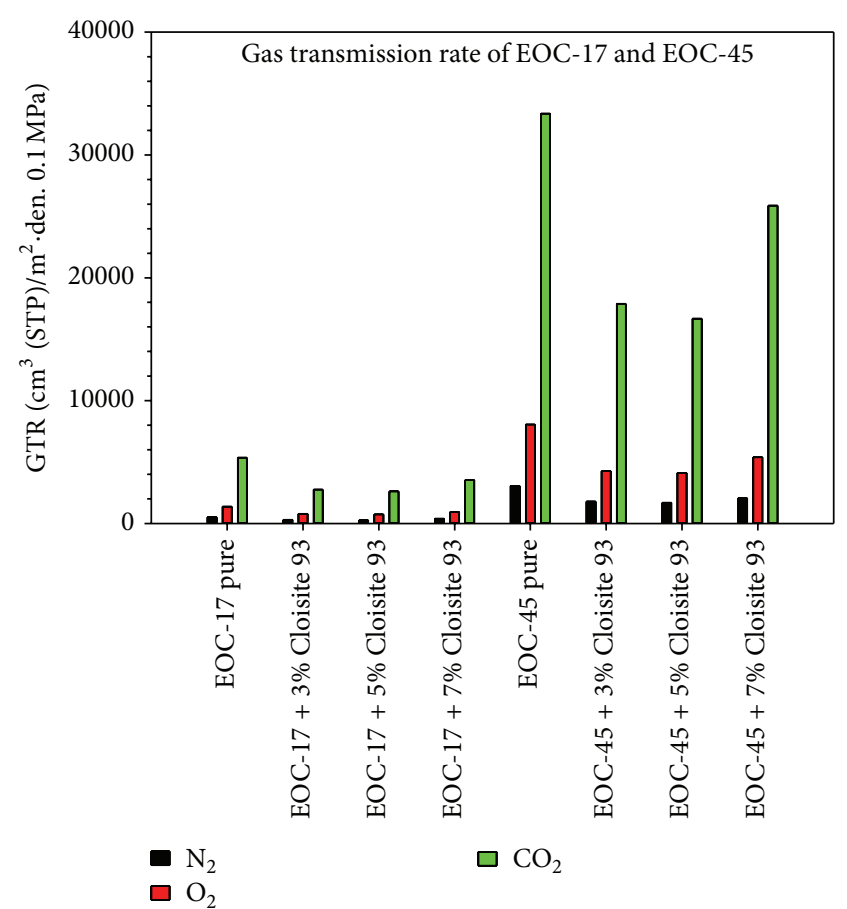

(a)

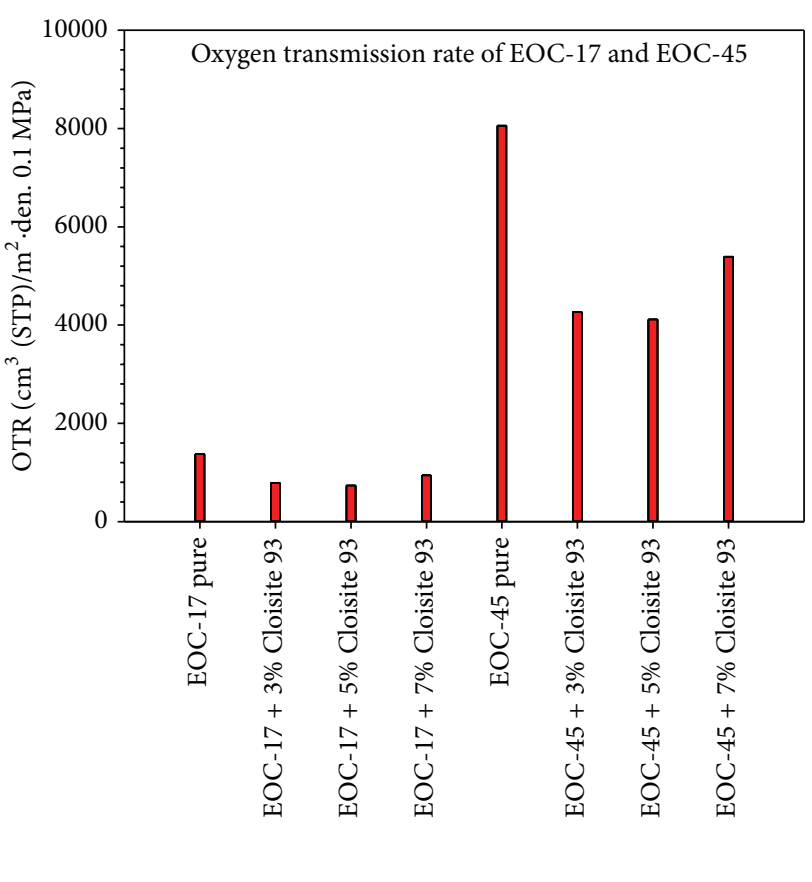

(b)

Figure 6: Barrier properties of EOC-17 (Engage 8540) and EOC-45 (Engage 8842): (a) gas transmission rate and (b) oxygen transmission rate.

According to the recorded results, it is possible to observe that incomplete montmorillonite exfoliation has taken place, but as discussed below, despite the incomplete exfoliation shown by XRD measurement, a certain improvement of some qualities observed has been proved.

Better results in X-ray diffraction can be observed in the case of EOC-45, where curves of filled materials compared with pure EOC sample are almost identical, with no significantly different peaks in the area of Cloisite 93A. In contrary, the curve of a composite of EOC-17 exhibits very noticeable peak, almost the same, like origin Cloisite 93A. This can be connected with the different EOC sample structure.

Figure 7 (a) illustrates a small shift in diffraction angle towards lower value corresponding to small increase of $D$ spacing (see Table 6) from 2.56 to $2.72 \mathrm{~nm}$ in case of EOC17 nanocomposite. This could be interpreted as intercalation.
TABLE 6: $D$-spacing of clay and filled EOC-17.

\begin{tabular}{lc}
\hline Composotion & $D$-spacing $(\mathrm{nm})$ \\
\hline EOC-17 $+5 \%$ Cloisite 93 & 2.728 \\
Cloisite 93 & 2.562 \\
\hline
\end{tabular}

Quite different scenario is recorded for EOC-45 nanocomposite in Figure 7(b). The peak has almost completely disappeared which can be interpreted as exfoliation. The presence of a small peak at $4.2^{\circ}$ corresponding to $D$-spacing being $2.21 \mathrm{~nm}$ can be explained by a distribution of $D$-spacing in original Cloisite 93 ranging from 2.2 to $2.7 \mathrm{~nm}$. During the melt-mixing the clay with larger $D$-spacing $(2.3 \sim 2.7 \mathrm{~nm})$ got exfoliated while small amount of clay with $D$-spacing $2.2 \mathrm{~nm}$ remained. 


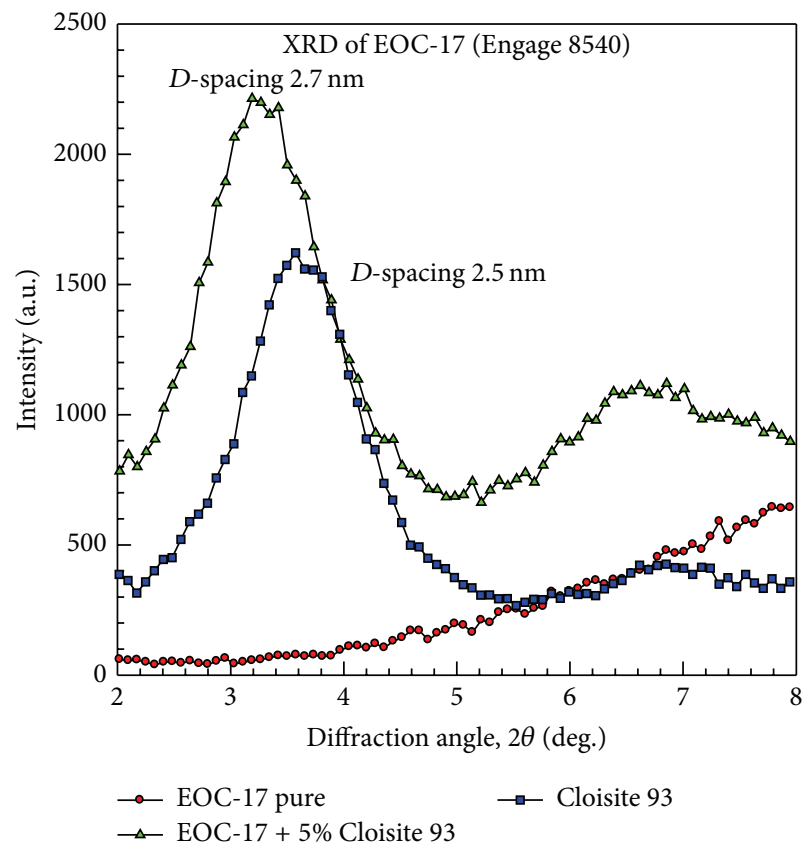

(a)

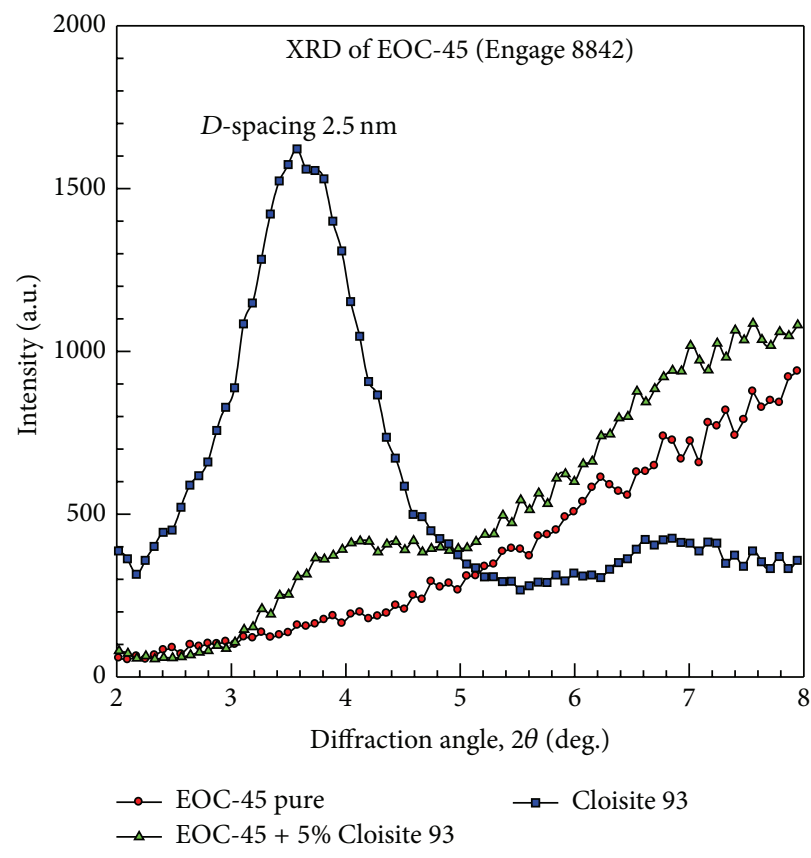

(b)

FIgUre 7: XRD graphs of EOC: (a) EOC-17 (Engage 8540) with 5 wt.\% Cloisite 93 and (b) EOC-45 (Engage 8842) with 5 wt.\% Cloisite 93.

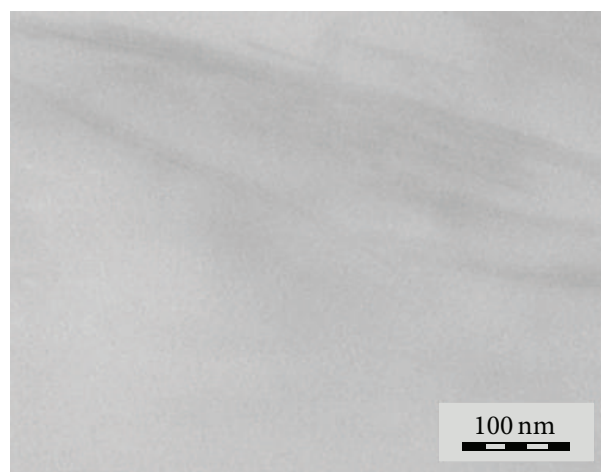

(a)

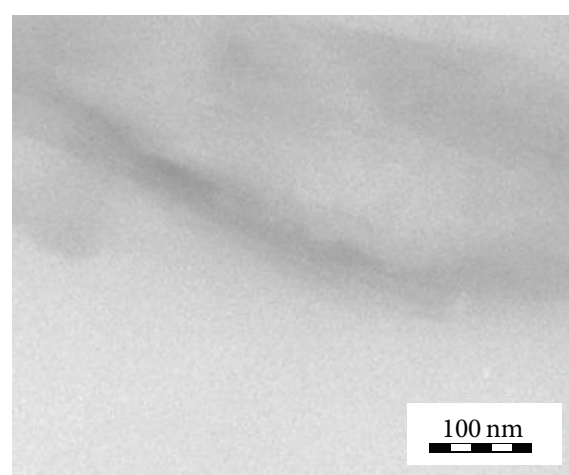

(b)

FIgURE 8: TEM pictures of (a) EOC-45 (Engage 8842) with 5 wt.\% Cloisite 93 and (b) EOC-45 (Engage 8842) with 7 wt.\% Cloisite 93.

3.5. Analysis of the Morphology by Transmission Electron Microscopy (TEM). The mixing was quite successful for both EOCs as it comes from results of TEM analysis. In Figures 8 and 9 a comparison of the distribution of nanofiller in a matrix of EOC-17 with different contents of clay can be seen. Distribution in both cases is about the same, but images suggest that in the case of EOC-17 with 5 and 7 wt.\% nanofiller in polymer matrix the exfoliation is worse.

TEM results confirm previous conclusions from XRD indicating better exfoliation of nanofiller in case of EOC-45.

The similar situation is also shown in Figure 9. The distribution and exfoliation of nanofiller in the polymer matrix is correct, but only for 5 wt.\% Cloisite 93.

According to our experience with filled polymers, $5 \mathrm{wt} . \%$ nanofiller filling is optimal in the polymer matrix.
This concentration leads to the exfoliation of the filler particles in the polymer. While when $7 \mathrm{wt} . \%$ nanofiller is used, not only the exfoliation is not good but even agglomerates can be formed.

3.6. Differential Scanning Calorimetry (DSC). Previous tests show that the best performance is at about $5 \%$ of nanofiller in the polymer matrix. In further tests, such as the DSC and FTIR, the samples are compared in particular with a $5 \mathrm{wt} . \%$ concentration.

DSC curve of pure EOC-17 (see Figure 10(a)) shows melting temperature of $108.3^{\circ} \mathrm{C} 5 \%$ of Cloisite causes the melting point to drop slightly to $106.2^{\circ} \mathrm{C}$. The peak occurring at $126^{\circ} \mathrm{C}$ (after Cloisite 93 addition) could be assigned to the PE-MA 


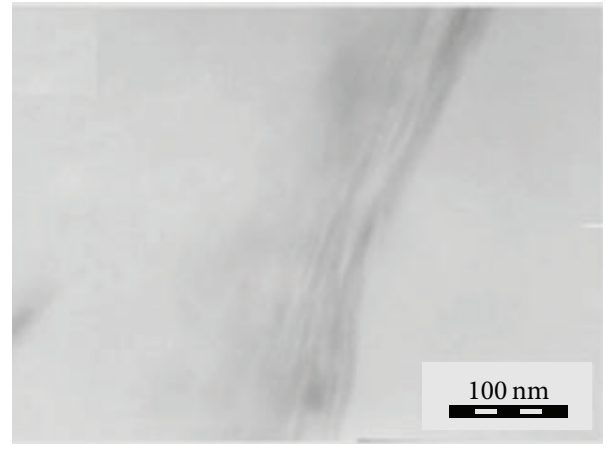

(a)

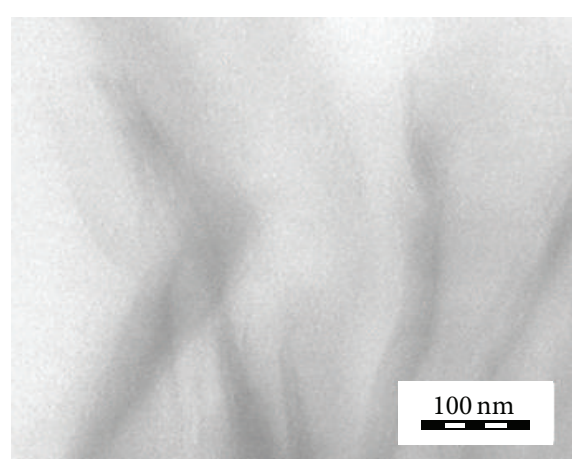

(b)

Figure 9: TEM pictures of (a) EOC-17 (Engage 8540) with 5 wt.\% Cloisite 93 and (b) EOC-17 (Engage 8540) with 7 wt.\% Cloisite 93.

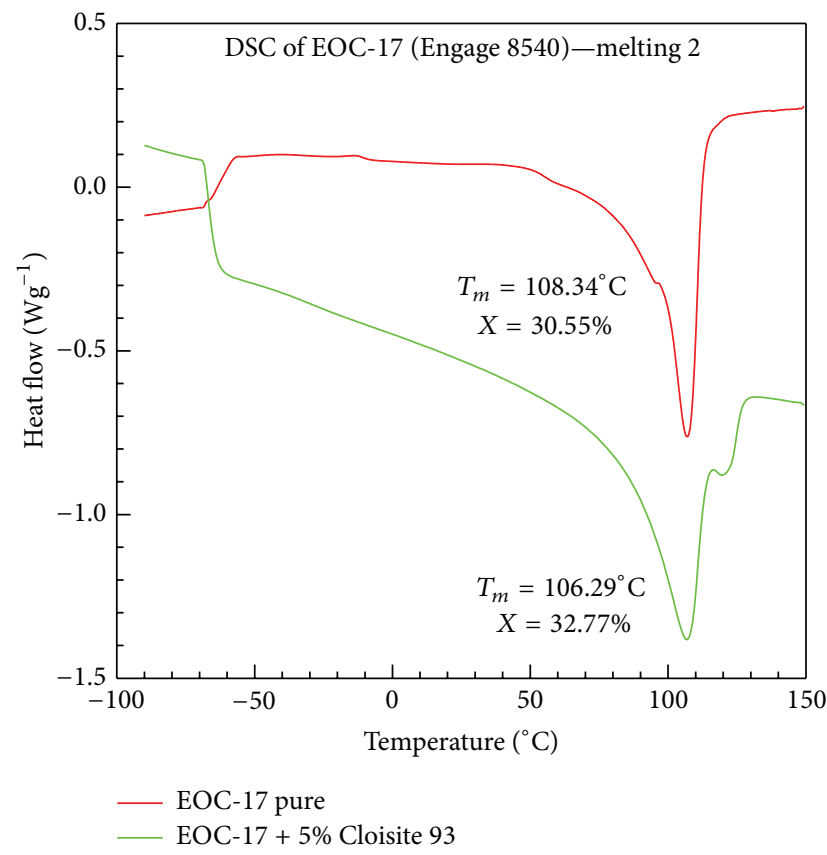

(a)

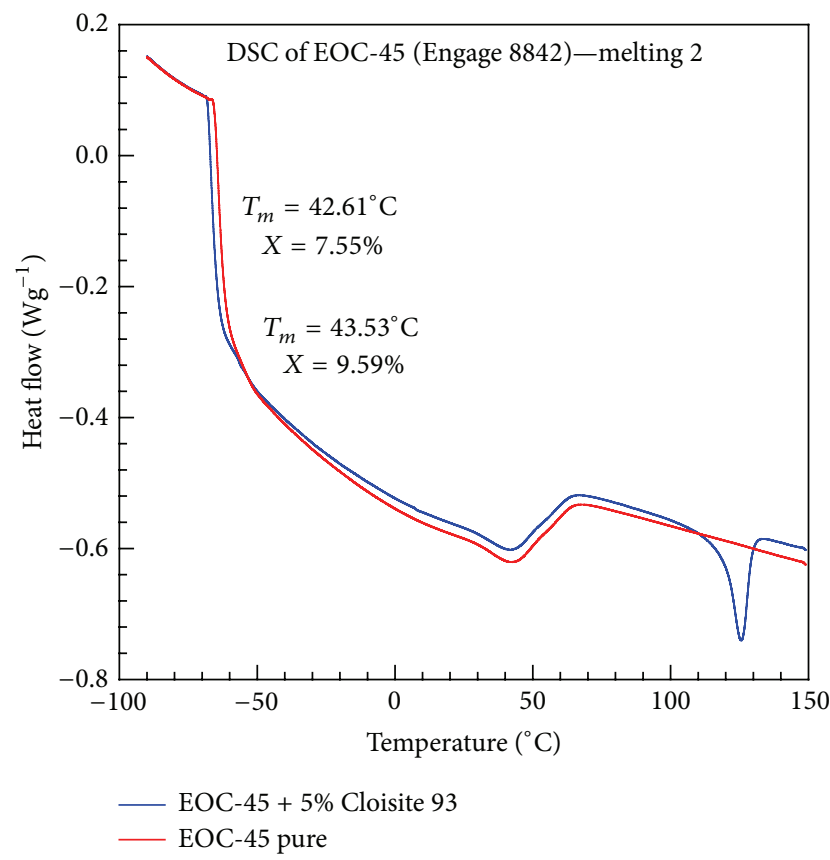

(b)

Figure 10: DSC graph of (a) EOC-17 (Engage 8540) with 5 wt.\% Cloisite 93-melting 2 and (b) EOC-45 (Engage 8842) with 5 wt.\% Cloisite 93-melting 2.

presence. However, crystallization curves differ significantly; pure EOC crystallizes at $88.3^{\circ} \mathrm{C}$, blending Cloisite 93 into EOC leads to the higher crystallization temperature of $89.4^{\circ} \mathrm{C}$, and additional peak occurs at $105^{\circ} \mathrm{C}$. The reason for two crystallization peaks is a low percentage of octene units. Cloisite 93 causes a shift in crystallization peaks which explains two peaks of a blend compared to two peaks of pure EOC. We can speculate that Cloisite 93 can influence crystallization ability of long base ethylene chains but does not affect short octene chains.

The exfoliation of nanoclay in EOC-17 was not perfect (shown by XRD and TEM), and some aggregates of clay remained. These aggregates acted most likely as nucleating agents. Therefore, the crystallization temperature increased about $2^{\circ} \mathrm{C}$.
This effect is much more visible in a second nanocomposite, EOC-45 with Cloisite 93 (Figures 10(b) and 11(b)) - in this case, pure polymer melts at $43.5^{\circ} \mathrm{C}$, Cloisite 93 causes shift peak at $42.6^{\circ} \mathrm{C}$ of pure EOC- 45 , and additional peak at $126^{\circ} \mathrm{C}$ is visible (comes probably from $\mathrm{PE}-\mathrm{MA}$ compatibilizer). Pure EOC- 45 crystallizes at temperature $18.8^{\circ} \mathrm{C}$ and filled at $16.1^{\circ} \mathrm{C}$; peak at $120^{\circ} \mathrm{C}(\mathrm{PE}-\mathrm{MA})$ remains.

Due to mentioned effect at crystallization and a higher octene content of EOC-45, peak appearance could be caused by a combination of both factors. Melting curves show that similar behavior of Cloisite 93 causes forming of the additional peak at high temperature and a slight drop in a melting temperature. The percent crystallinity was calculated using a value of $\Delta H^{\circ}{ }_{m}=290 \mathrm{Jg}^{-1}$ for the heat of fusion of $100 \%$ crystalline polyethylene [32]. 
TABLE 7: FTIR measurement and comparison of the peak area before UV degradation and peak area after 46 days of UV degradation.

\begin{tabular}{lccc}
\hline Composition & $\begin{array}{c}\text { Peak area } \\
1810.920-1508.135 \mathrm{~cm}^{-1}\end{array}$ & $\begin{array}{c}\text { Peak area } 46 \text { days } \\
1810.920-1508.135 \mathrm{~cm}^{-1}\end{array}$ & $\begin{array}{c}\text { Peak height at 1720 } \mathrm{cm}^{-1} \\
46 \text { days (absorbance) }\end{array}$ \\
\hline EOC-17 pure & 1.347 & 6.828 & 0.111 \\
EOC-17 + 5\% Cloisite 93 & 1.517 & 4.367 & 0.112 \\
EOC-45 pure & 1.437 & 5.273 & 0.133 \\
EOC-45 + 5\% Cloisite 93 & 1.242 & 3.476 & 0.102 \\
\hline
\end{tabular}

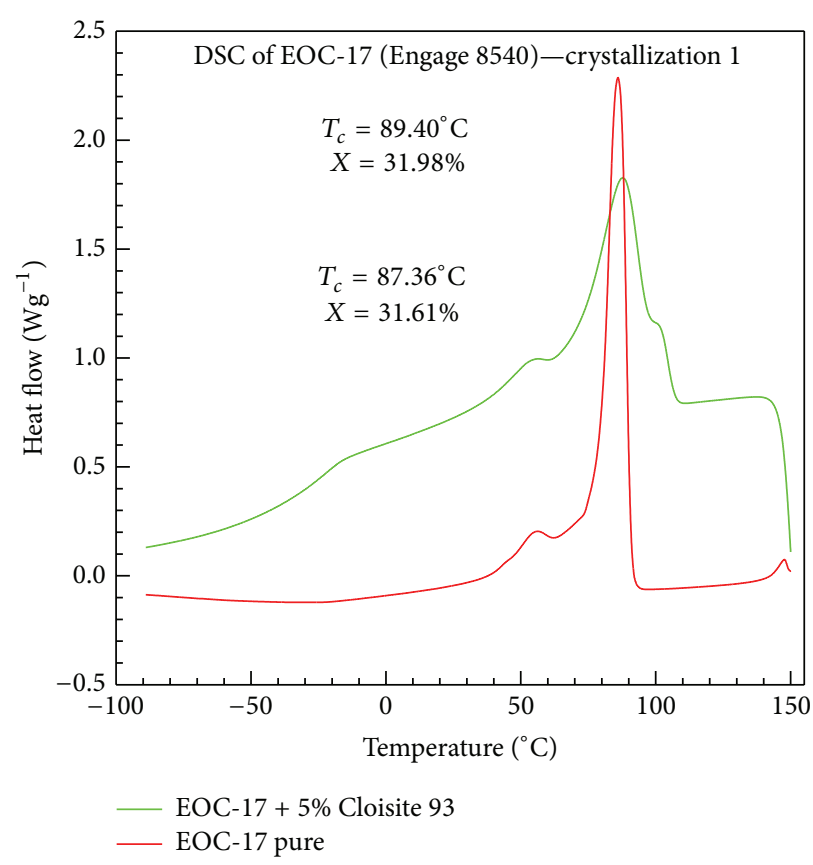

(a)

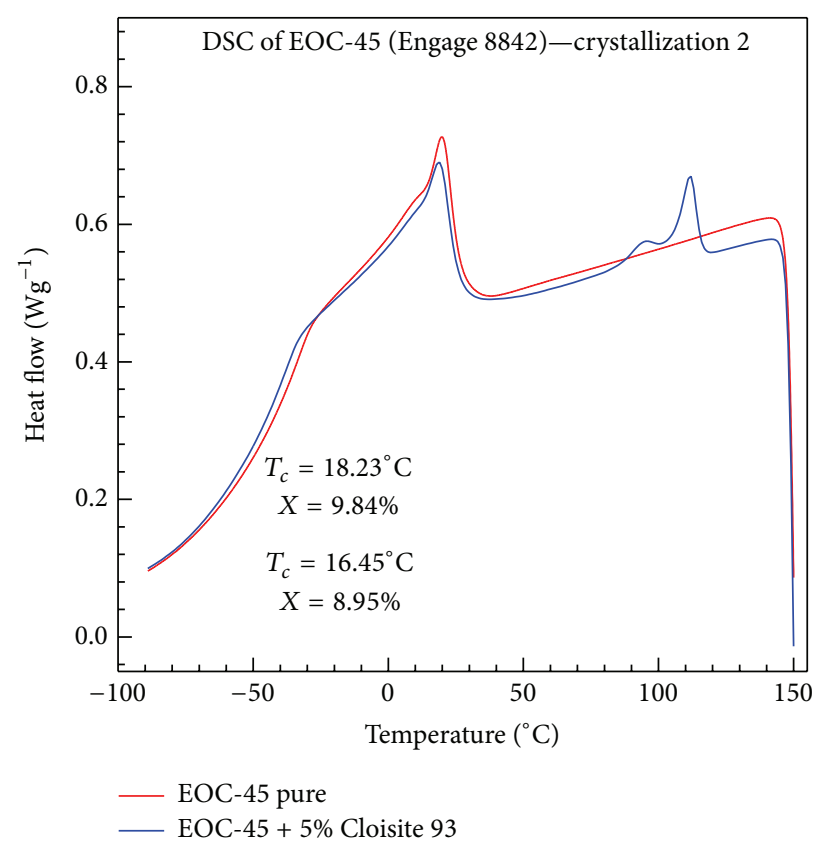

(b)

Figure 11: DSC graph of (a) EOC-17 (Engage 8540) with 5 wt.\% Cloisite 93-crystallization 2 and (b) EOC-45 (Engage 8842) with 5 wt.\% Cloisite 93-crystallization 2.

As shown by XRD and TEM the exfoliation of nanoclay in EOC-45 was better. This influenced rather broad melting peak and lower crystallization temperature. This time, there were no aggregates that could serve as nucleating agents.

3.7. Accelerated Weathering Test and FTIR. The samples underwent UV degradation in the device Xenotest Alpha for the period 46 days. At the beginning of the degradation test and at the end of degradation test FTIR analysis of all the measured samples was performed.

EOC chain is composed only of $\mathrm{CH}_{3}$ and $\mathrm{CH}_{2}$ groups. Typical peaks (see Figures 12 and 13) for these groups are in $2962 \mathrm{~cm}^{-1}$ for $\mathrm{CH}_{3}$ asymmetric valence (as. v.). $2872 \mathrm{~cm}^{-1}$ for $\mathrm{CH}_{3}$ symmetric valence (s. v.) and $2926 \mathrm{~cm}^{-1}$ for $\mathrm{CH}_{2}$ asymmetric valence (as. v.). $2853 \mathrm{~cm}^{-1}$ for $\mathrm{CH}_{2}$ symmetric valence (s. v.).

By FTIR analysis change in the area of $1810 \mathrm{~cm}^{-1}$ to $1681 \mathrm{~cm}^{-1}$ was monitored. This maximum corresponds to the vibration of $\mathrm{C}=\mathrm{O}$ bonds that are generated in the degradation processes. The results show that the largest increase in the area of the pure samples EOC-17 and EOC-45 was recorded.
The higher change of EOC-17 pure was observed. Filled specimens show a smaller percentage of degradation of the matrix (see Table 7). During sample degradation probably molecular weight decreases and leads to the breaking of chains.

Filling 5 wt.\% of the modified Cloisite 93 has improved observed characteristics, especially in the longer term. In this case, the impact modifier can be expected during the course of degradation.

The difference between the materials in the curves may be caused by different densities of both the EOC and various contents of octene groups. The protection against UV degradation was better in the case of EOC-45 nanocomposite most likely due to a better dispersion of clay.

The presence of the filler (Cloisite 93) in the EOC45 matrix reduces degradation of the nanocomposite in comparison to pure EOC-45, which may be due to a higher level of exfoliation of the MMT platelets in polymer matrix because these exfoliated filler particles can protect EOC's polymer chain against the degradation impacts. Table 7 shows peak height at $1720 \mathrm{~cm}^{-1} 46$ days (absorbance) and Figure 13 


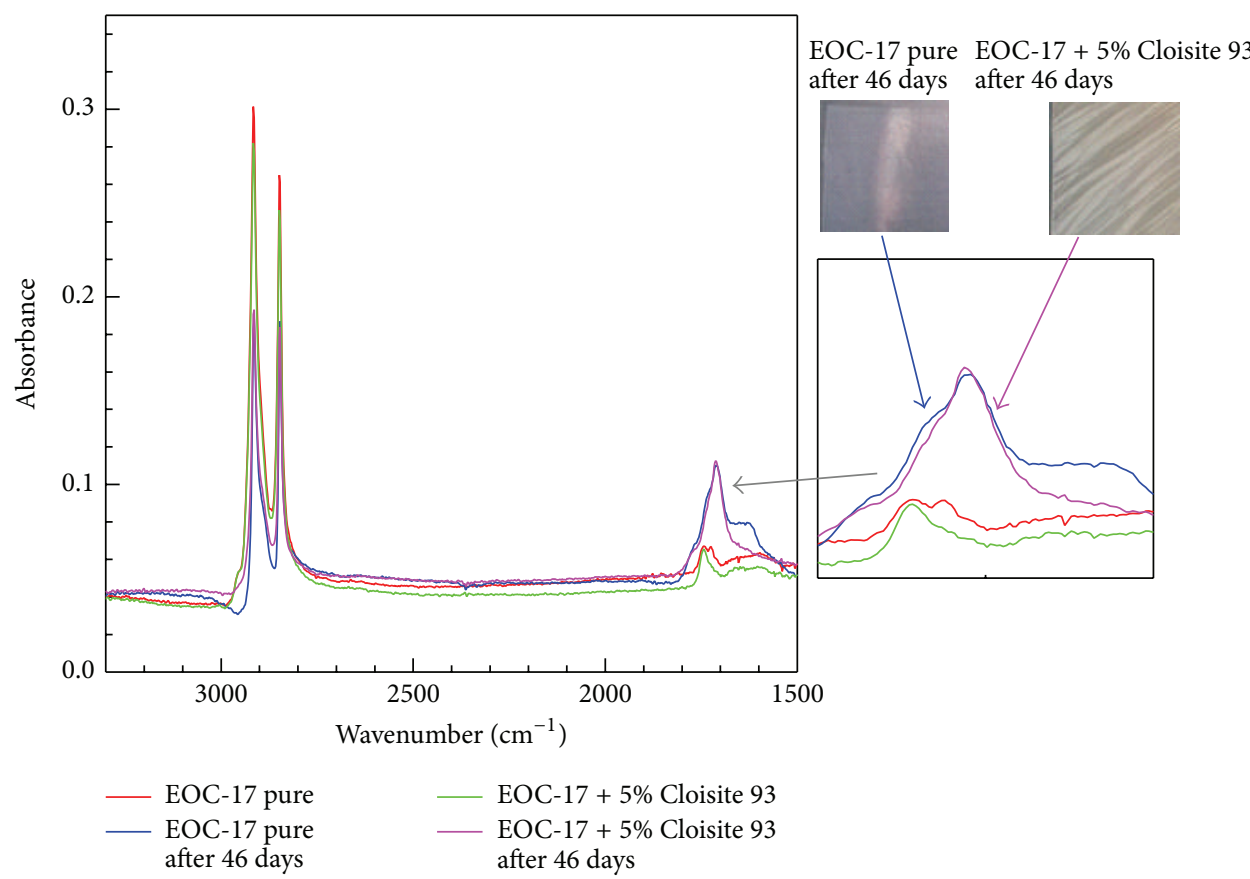

FIGURE 12: FTIR graph of EOC-17 (Engage 8540) pure and EOC-17 with 5 wt.\% Cloisite 93 and details of area 1810 to $1681 \mathrm{~cm}^{-1}$. Picture of change of EOC-17 pure after 46 days of UV degradation. EOC-17 + 5\% Cloisite 93 after 46 days of UV degradation.

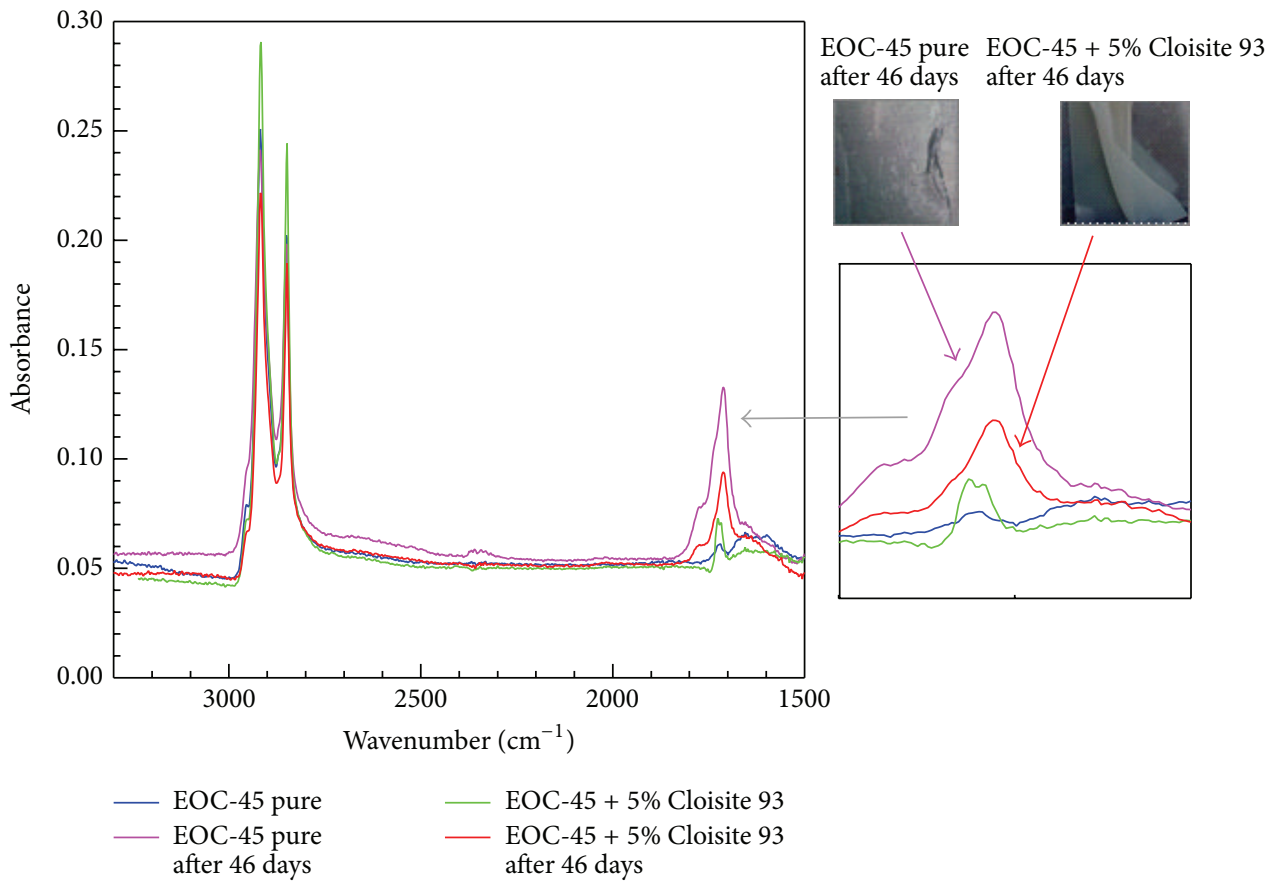

FIGURE 13: FTIR graph of EOC-45 (Engage 8842) pure and EOC-45 with 5 wt.\% Cloisite 93 and details of area 1810 to $1681 \mathrm{~cm}^{-1}$. Picture of change of EOC-45 pure after 46 days of UV degradation. EOC- $45+5 \%$ Cloisite 93 after 46 days of UV degradation. 
shows decrease from 0.133 for pure EOC- 45 to 0.102 for EOC45 with 5 wt.\% Cloisite 93.

The results of FTIR confirm the tests of the DMA, XRD, TEM, and DCS for better exfoliation of nanofiller in polymer matrix EOC-45. The perfect exfoliation of nanofiller in the polymer matrix may be caused by higher content octene units.

\section{Conclusion}

Ethylene-octene copolymer matrices with one type of commercial nanofiller with different concentration were prepared and observed. Because of using mentioned materials for food packaging, the mechanical properties of prepared samples, barrier, morphological, thermal, and UV degradation properties were checked.

Comparison of mechanical properties and exfoliation of the nanofiller in the polymer matrix was observed. Strengthening effect of Cloisite is stronger in the EOC-45 mixture when compared to EOC-17. In addition to increased modulus, glass transmission and melting temperature are slightly shifted to higher temperatures. The very good result in the case of mechanical and barrier properties were found, especially for EOC matrix with 5 wt.\% Cloisite 93. The EOC reaches the maximum value EOC- 45 with 5 wt.\% Cloisite 93, on the opposite side of the lowest values in the EOC-17+ 3\% Cloisite 93 for mechanical properties. EOC-17 pure and its blends with Cloisite 93 show a linear decrease of tan delta $(\tan \delta)$ with increasing frequency. The addition of Cloisite 93 causes $\tan \delta$ to drop significantly at high frequencies whereas the low frequencies are affected only marginally.

Filling 5 wt.\% of the modified Cloisite 93 has improved FTIR observed characteristics, especially in the longer term. In this case, the impact modifier can be expected during the course of degradation. Platelets of montmorillonite can overlap and may cause deterioration of the desired properties. The goal of the production of polymer nanocomposites is to achieve the full exfoliation. It was found that nanofillers in polymer matrix mechanics affect polymer properties. It is possible to state that good exfoliation of fillers can improve mechanical properties of nanocomposites. Nevertheless, the degree of exfoliation and orientation of the platelets is the most critical parameter.

\section{Conflict of Interests}

The authors declare that there is no conflict of interests regarding the publication of this paper.

\section{Acknowledgments}

This paper (specified by the fact) was written with the support by the Projects TA03010799 and IGA/FT/2015/007 TBU in Zlin.

\section{References}

[1] F. Bertini, M. Canetti, G. Audisio, G. Costa, and L. Falqui, "Characterization and thermal degradation of polypropylenemontmorillonite nanocomposites," Polymer Degradation and Stability, vol. 91, no. 3, pp. 600-605, 2006.

[2] S. P. Zhu, J. Y. Chen, H. L. Li, and Y. Cao, "Effect of polymer matrix/montmorillonite compatibility on morphology and melt rheology of polypropylene nanocomposites," Journal of Applied Polymer Science, vol. 128, no. 6, pp. 3876-3884, 2013.

[3] F. Lei, S. Yang, M. T. Yang, J. Li, and S. Y. Guo, "Exfoliation of organic montmorillonite in iPP free of compatibilizer through the multistage stretching extrusion," Polymer Bulletin, vol. 71, no. 12, pp. 3261-3273, 2014.

[4] L. B. Fitaroni, J. A. de Lima, S. A. Cruz, and W. R. Waldman, "Thermal stability of polypropylene-montmorillonite clay nanocomposites: limitation of the thermogravimetric analysis," Polymer Degradation and Stability, vol. 111, pp. 102-108, 2015.

[5] X. Yin and G. S. Hu, "Effects of organic montmorillonite with different interlayer spacing on mechanical properties, crystallization and morphology of polyamide 1010/nanometer calcium carbonate nanocomposites," Fibers and Polymers, vol. 16, no. 1, pp. 120-128, 2015.

[6] K.-B. Yoon, H.-D. Sung, Y.-Y. Hwang, S. K. Noh, and D.-H. Lee, "Modification of montmorillonite with oligomeric amine derivatives for polymer nanocomposite preparation," Applied Clay Science, vol. 38, no. 1-2, pp. 1-8, 2007.

[7] L. B. Manfredi, D. Puglia, A. Tomasucci, J. M. Kenny, and A. Vázquez, "Influence of clay modification on the properties of resol nanocomposites," Macromolecular Materials and Engineering, vol. 293, no. 11, pp. 878-886, 2008.

[8] Z. Qian, S. Zhang, and M. Yang, "Effect of clay modification on photo-oxidation of polyethylene/clay nanocomposites," Polymers and Polymer Composites, vol. 16, no. 8, pp. 535-546, 2008.

[9] X. Y. Meng, Z. Wang, X. H. Du, Y. H. Wang, and T. Tang, "Exfoliation of organically modified montmorillonite driven by molecular diffusion in maleated polypropylene," Journal of Applied Polymer Science, vol. 113, no. 1, pp. 678-684, 2009.

[10] J. Soulestin, B. J. Rashmi, S. Bourbigot, M.-F. Lacrampe, and P. Krawczak, "Mechanical and optical properties of polyamide 6/clay nanocomposite cast films: influence of the degree of exfoliation," Macromolecular Materials and Engineering, vol. 297, no. 5, pp. 444-454, 2012.

[11] T. Kuila, T. Tripathy, and J. H. Lee, "Polyolefin-based polymer nanocomposites," in Advances in Polymer Nanocomposites: Types and Applications, pp. 181-215, Woodhead Publishing, 2012.

[12] F. Zandi, M. Rezaei, and A. Kasiri, "Effect of nanoclay on the physical-mechanical and thermal properties and microstructure of extruded noncross-linked LDPE nanocomposite foams," Composite Science and Technology, vol. 471-472, pp. 751-756, 2011.

[13] P. Santamaría, J. I. Eguiazabal, and J. Nazabal, "Dispersion and mechanical properties of a nanocomposite with an organoclay in an ionomer-compatibilized LDPE matrix," Journal of Applied Polymer Science, vol. 119, no. 3, pp. 1762-1770, 2011.

[14] R. Theravalappil, P. Svoboda, J. Vilcakova, S. Poongavalappil, P. Slobodian, and D. Svobodova, "A comparative study on the electrical, thermal and mechanical properties of ethylene-octene copolymer based composites with carbon fillers," Materials \& Design, vol. 60, pp. 458-467, 2014. 
[15] C. Grein, M. Gahleitner, and K. Bernreitner, "Mechanical and optical effects of elastomer interaction in polypropylene modification: ethylene-propylene rubber, poly-(ethylene-co-octene) and styrene-butadiene elastomers," Express Polymer Letters, vol. 6, no. 9, pp. 688-696, 2012.

[16] R. Rajeshbabu, U. Gohs, K. Naskar, V. Thakur, U. Wagenknecht, and G. Heinrich, "Preparation of polypropylene (PP)/ethylene octene copolymer (EOC) thermoplastic vulcanizates (TPVs) by high energy electron reactive processing," Radiation Physics and Chemistry, vol. 80, no. 12, pp. 1398-1405, 2011.

[17] P. Svoboda, R. Theravalappil, D. Svobodova et al., "Elastic properties of polypropylene/ethylene-octene copolymer blends," Polymer Testing, vol. 29, no. 6, pp. 742-748, 2010.

[18] R. R. Babu, N. K. Singha, and K. Naskar, "Dynamically vulcanized blends of polypropylene and ethylene octene copolymer: influence of various coagents on mechanical and morphological characteristics," Journal of Applied Polymer Science, vol. 113, no. 5, pp. 3207-3221, 2009.

[19] D. Pizele, V. Kalkis, R. M. Meri, T. Ivanova, and J. Zicans, "On the mechanical and thermomechanical properties of lowdensity polyethylene/ethylene- $\alpha$-octene copolymer blends," Mechanics of Composite Materials, vol. 44, no. 2, pp. 191-196, 2008.

[20] M. Jaziri, N. Mnif, V. Massardier-Nageotte, and H. PerierCamby, "Rheological, thermal, and morphological properties of blends based on poly(propylene), ethylene propylene rubber, and ethylene-1-octene copolymer that could result from end of life vehicles: effect of maleic anhydride grafted poly(propylene)," Polymer Engineering and Science, vol. 47, no. 7, pp. 1009-1015, 2007.

[21] M. J. O. C. Guimarães, F. M. B. Coutinho, M. C. G. Rocha, M. Farah, and R. E. S. Bretas, "Effect of molecular weight and long chain branching of metallocene elastomers on the properties of high density polyethylene blends," Polymer Testing, vol. 22, no. 8, pp. 843-847, 2003.

[22] A. L. N. Silva, M. C. G. Rocha, and F. M. B. Coutinho, "Study of rheological behavior of elastomer/polypropylene blends," Polymer Testing, vol. 21, no. 3, pp. 289-293, 2002.

[23] R. R. Babu, N. K. Singha, and K. Naskar, "Phase morphology and melt rheological behavior of uncrosslinked and dynamically crosslinked polyolefin blends: role of macromolecular structure," Polymer Bulletin, vol. 66, no. 1, pp. 95-118, 2011.

[24] R. R. Babu, N. K. Singha, and K. Naskar, "Interrelationships of morphology, thermal and mechanical properties in uncrosslinked and dynamically crosslinked PP/EOC and PP/EPDM blends," Express Polymer Letters, vol. 4, no. 4, pp. 197209, 2010.

[25] X. Yan, X. Xu, T. Zhu, C. Zhang, N. Song, and L. Zhu, "Phase morphological evolution and rheological properties of polypropylene/ethylene-octene copolymer blends," Materials Science and Engineering A, vol. 476, no. 1-2, pp. 120-125, 2008.

[26] N. Tortorella and C. L. Beatty, "Morphology and mechanical properties of impact modified polypropylene blends," Polymer Engineering and Science, vol. 48, no. 11, pp. 2098-2110, 2008.

[27] W.-Y. Guo and B. Peng, "Rheology, morphology, and mechanical and thermal properties of blends of propylene based plastomer and ethylene/1-octene copolymer," Journal of Elastomers and Plastics, vol. 40, no. 1, pp. 61-76, 2008.

[28] K. Wang, F. Addiego, N. Bahlouli, S. Ahzi, Y. Rémond, and V. Toniazzo, "Impact response of recycled polypropylene-based composites under a wide range of temperature: effect of filler content and recycling," Composites Science and Technology, vol. 95, pp. 89-99, 2014.

[29] O. Saravari, H. Waipunya, and S. Chuayjuljit, "Effects of ethylene octene copolymer and ultrafine wollastonite on the properties and morphology of polypropylene-based composites," Journal of Elastomers and Plastics, vol. 46, no. 2, pp. 175-186, 2014.

[30] I. Bochkov, R. M. Meri, J. Zicans, T. Ivanova, and J. Grabis, "Multi-component composites based on polypropylene. Ethylene-octene copolymer and zinc oxide," Engineering Materials \& Tribology XXII, vol. 604, pp. 130-133, 2014.

[31] S. Bagheri-Kazemabad, D. Fox, Y. H. Chen, H. Z. Zhang, and B. Q. Chen, "Morphology and properties of polypropylene/ethylene-octene copolymer/clay nanocomposites with double compatibilizers," Polymers for Advanced Technologies, vol. 25, no. 10, pp. 1116-1121, 2014.

[32] P. Dias, Y. J. Lin, B. Poon, H. Y. Chen, A. Hiltner, and E. Baer, "Adhesion of statistical and blocky ethylene-octene copolymers to polypropylene," Polymer, vol. 49, no. 12, pp. 2937-2946, 2008. 

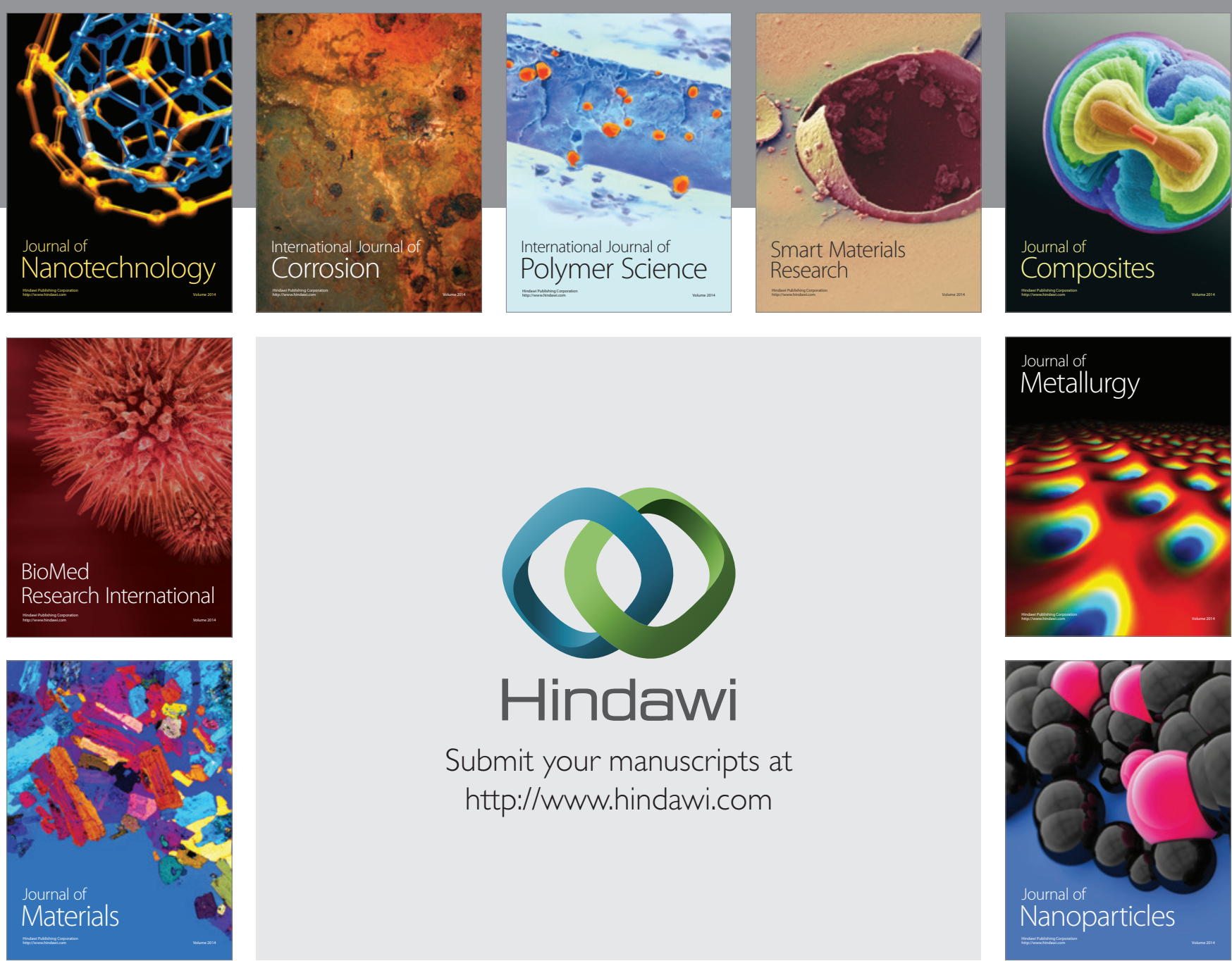

\section{Hindawi}

Submit your manuscripts at

http://www.hindawi.com

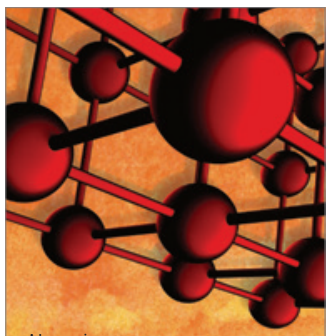

Materials Science and Engineering
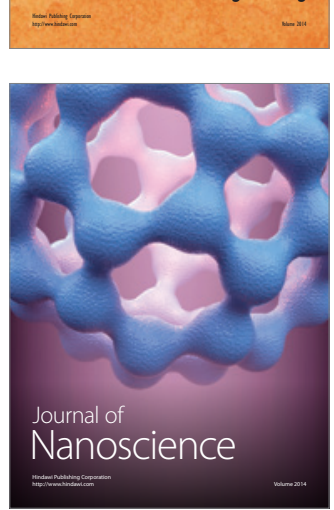
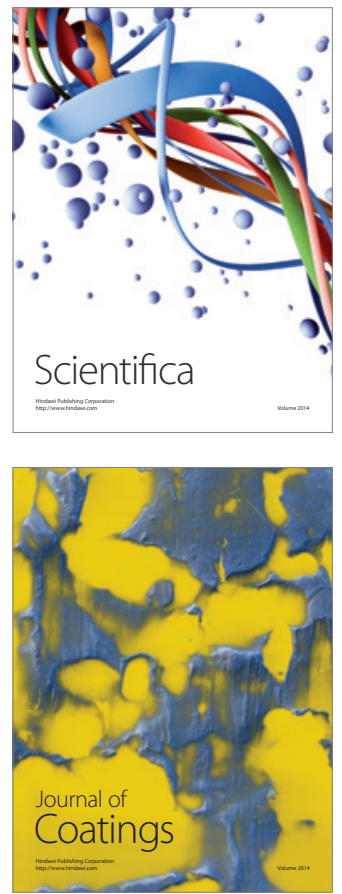
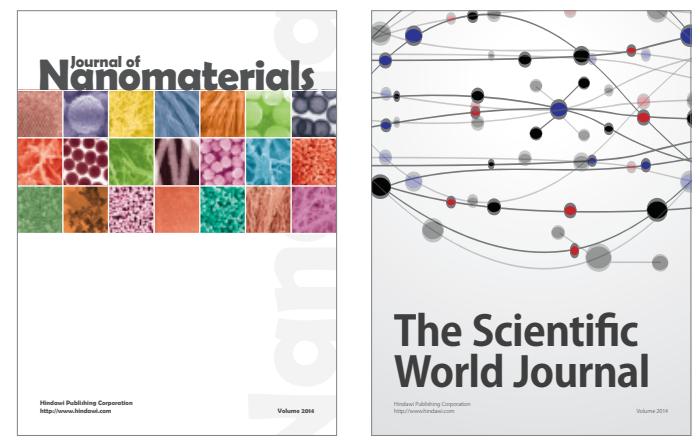

The Scientific World Journal
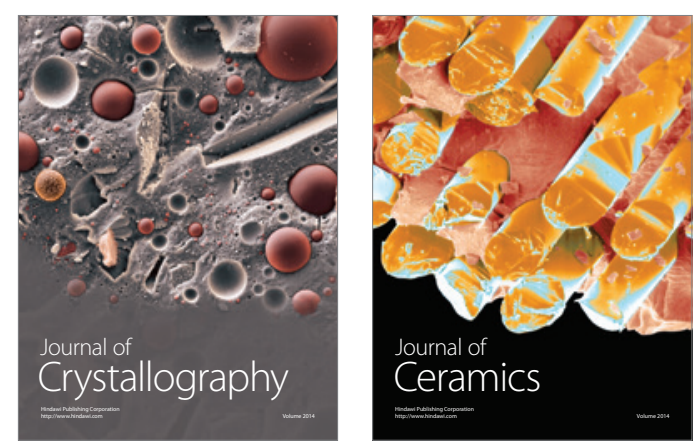
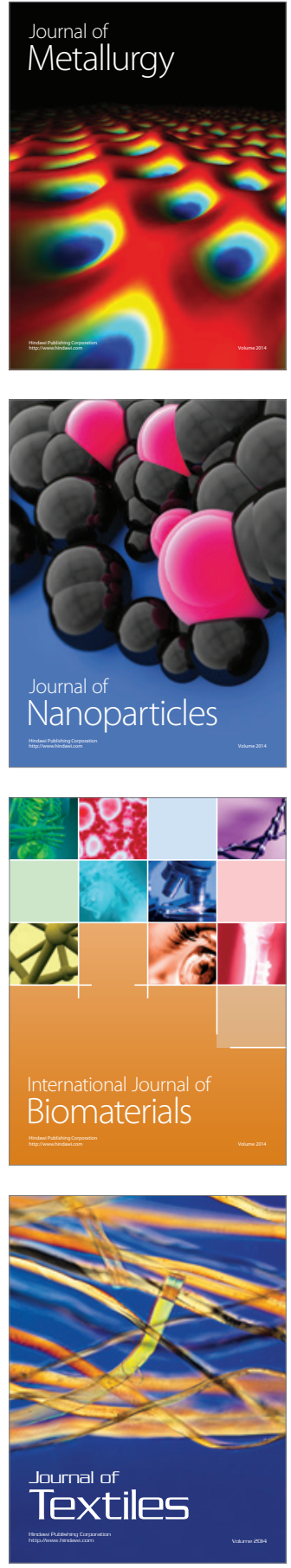